\title{
Employers' age-related norms, stereotypes and ageist preferences in employment
}

\author{
Jaap Oude Mulders \\ Netherlands Interdisciplinary Demographic Institute (NIDI-KNAW)/ \\ University of Groningen, The Hague, The Netherlands
}

\begin{abstract}
Purpose - Social norms about the timing of retirement and stereotypes about qualities of younger and older workers are pervasive, but it is unclear how they relate to employers' ageist preferences. The purpose of this paper is to study the effects of employers' retirement age norms and age-related stereotypes on their preferences for younger or older workers in three types of employment practices: hiring a new employee; offering training; and offering a permanent contract.

Design/methodology/approach - Survey data from 960 Dutch employers from 2017 are analysed to study employers' preferences for younger or older workers. Effects of organisations' and managers' characteristics, retirement age norms and stereotypes are estimated with multinomial logistic regression analyses.

Findings - Many employers have a strong preference for younger workers, especially when hiring a new employee, while preferences for older workers are highly uncommon. Higher retirement age norms of employers are related to a lower preference for younger workers in all employment decisions. When employers are more positive about older workers' soft qualities (such as reliability and social skills), but not about their hard qualities (such as their physical capacity and willingness to learn), they rate older workers relatively more favourable for hiring and offering training, but not for providing a permanent contract.

Originality/value - This is one of the first studies to estimate the effects of retirement age norms and age-related stereotypes on ageist preferences for a diverse set of employment practices.
\end{abstract}

Keywords Ageism, Social norms, Older workers, Younger workers, Labour market

Paper type Research paper

\section{Introduction}

In the previous two decades, population ageing has created the need for longer working lives in countries all over the world. Due to declining fertility rates and increasing life expectancy, the average age of the workforce and that of the entire population is increasing, which has created the need for older individuals to postpone their exit from the labour market and stay involved with paid employment for a prolonged period. Indeed, many countries have implemented institutional reforms to the labour market and retirement systems to discourage early retirement, and instead support prolonged employment of older workers (OECD, 2017).

However, it is well established in the literature that social norms and stereotypes may negatively affect employment opportunities and behaviour of older workers. Social norms about the appropriate timing of retirement may affect retention of older workers and organisations' support for working beyond standard retirement age (Karpinska et al., 2013b; Oude Mulders et al., 2017). In addition, several negative stereotypes are commonly associated with older workers, which may affect their opportunities in the labour market. For example, older workers are often perceived to have diminishing physical and mental capacities, a decreased willingness

(C) Jaap Oude Mulders. Published by Emerald Publishing Limited. This article is published under the Creative Commons Attribution (CC BY 4.0) licence. Anyone may reproduce, distribute, translate and create derivative works of this article (for both commercial and non-commercial purposes), subject to full attribution to the original publication and authors. The full terms of this licence may be seen at http://creativecommons.org/licences/by/4.0/legalcode

This work was supported by Netspar (Grant No. IRG2016.03). The author would like to thank two anonymous reviewers for their comments that helped improve this work.

Employers'

age-related

norms

Received 30 October 2018 Revised 7 May 2019

2 July 2019

7 October 2019

Accepted 7 October 2019 
IJM

41,5

and capacity to learn new things, and are overall thought to be less productive in their work than younger workers (Posthuma and Campion, 2009; Van Dalen et al., 2010; Harris et al., 2018). On the other hand, there are also positive stereotypes about older workers, such as that they are more reliable and committed, and possess better social skills than younger workers (Kite et al., 2005; Harris et al., 2018). Even though such stereotypes may have no base in reality, or only a limited one, or may only be true in certain cases, they have been shown to exert a strong influence on real-world attitudes towards younger and older workers, of both employers and employees themselves ( $\mathrm{Ng}$ and Feldman, 2012). Such attitudes may then translate into employers preferring younger or older workers for different types of employment decisions, such as hiring a new employee and offering training, which will in turn affect real-world outcomes and opportunities for older workers to stay active in the labour market (Henkens, 2005). In addition, the experience of age discrimination by employees, often in implicit ways, may negatively affect their job satisfaction, commitment to work and plans to continue working (Zaniboni, 2015; Griffin et al., 2016; Marchiondo et al., 2019; Stypinska and Turek, 2017).

Even though differential treatment of people based on age is explicitly prohibited in many countries, evidence of ageist practices or age discrimination in employment is plentiful (e.g. Gordon and Arvey, 2004; Weiss and Maurer, 2004; Lindner et al., 2014; Neumark and Button, 2014; Oude Mulders et al., 2018). This may be because social norms about retirement and stereotypes about older and younger workers are deeply rooted in culture (Marcus and Fritzsche, 2016) and tied to population ageing (North and Fiske, 2015), making them pervasive and slow to change (Radl, 2012). Another reason may be that age discrimination is often implicit and difficult to prove in a legal setting. For example, Lindner et al. (2014) show that many individuals have ageist preferences in hiring situations, even when primed with equity norms that prescribe that it is forbidden to discriminate, and even when they perceive themselves to be objective in their decisions. On the other hand, Roscigno et al. (2007) show that many employers may be aware of their ageist preconceptions, but legitimise and rationalise their ageist behaviour, for example by invoking arguments based on increasing business costs (Conen et al., 2012; Ollier-Malaterre et al., 2013).

An important question is whether there is a direct link between employers' social norms and stereotypical views about younger and older workers on the one hand, and their ageist preferences in different types of relevant employment practices on the other hand. Here, ageism is, following the Oxford English Dictionary, understood to be "prejudice or discrimination on the grounds of a person's age" and can thus be targeted at anyone, although more commonly targeted at older persons (Ageism, n.d.). This paper aims to answer this question, by studying survey data from Dutch employers, collected in 2017, focusing on employers' preferences for younger or older workers in three distinct employment practices that may have long-term implications: hiring a new employee, offering training to an employee and offering a permanent contract to an employee. While hiring and offering training are commonly studied outcome variables, offering a permanent contract has not received much attention in the literature. Still, this is a very relevant employment decision in countries with a relatively high level of employment protection legislation, since a permanent contract (as opposed to a flexible or fixed-term contract) offers a much higher level of protection against unemployment. This can be especially relevant for older workers, since they may face especially harsh long-term effects of unemployment, such as severe income loss and low chances of re-employment (Wanberg et al., 2016; Heisig and Radl, 2017).

Since this study analyses data from Dutch employers, some background information on the labour market and institutional context of the Netherlands may be useful. In the last two decades, the Netherlands has been changing from a country where early exit from the labour market was heavily fiscally supported by the government and therefore very common, to a country where the government tries to promote and support working until higher ages through various policy reforms. Routes towards early exit, either through financially attractive early retirement schemes 
or through alternative routes such as with unemployment or disability benefits, have been severely restricted. At the same time, due to a 2012 policy reform, the eligibility age for the public pension has been steadily increasing from 65 years, to reach 67 years in 2021 . After that, the public pension age, to which also occupational retirement schemes are connected, will change in accordance with increases in the life expectancy projections, which, under current projections, will lead to a public pension age of about 71 years around the year 2060 (OECD, 2017). These institutional reforms and changing market forces have led to strong increases in labour force participation rates of older workers, average age at retirement and the proportion of employees working until the (increasing) public pension age (Visser et al., 2016). In addition, the Dutch labour market is known for a comparatively high level of employment protection legislation, where employers are responsible for high levels of severance pay in case of employee dismissal. This has led to a rise in popularity of more flexible forms of employment, such as temporary contracts, especially since the financial crisis of 2008 (OECD, 2014).

This paper is further structured as follows. Next, the theoretical background of the relation between age-related social norms, stereotypes about older and younger workers, and ageist employment practices will be discussed. Then, the methods of the empirical study are described, followed by the results. The paper concludes with a discussion section.

\section{Theoretical background}

\section{Retirement age norms}

Age-related social norms are commonly studied in life domains with little institutional regulation, such as family life and voluntary activities (Liefbroer and Billari, 2010). Even though the role of age-related social norms in employment settings has received much less attention in the literature, it is evident that certain types of age-related norms may affect behaviour of employers and employees (Settersten and Hagestad, 1996; Oude Mulders et al., 2017). Social norms are views about appropriate behaviour in certain situations, and the most commonly studied age-related social norm in employment settings is the retirement age norm, or the norm about the appropriate timing of retirement (Settersten and Hagestad, 1996; Radl, 2012). For example, in a series of vignette experiments, the retirement age norm of hiring managers has been shown to affect hiring of early retirees (Karpinska et al., 2013a), retention of older workers (Karpinska et al., 2013b) and hiring of retirees after mandatory retirement (Oude Mulders et al., 2014). Managers that hold a higher retirement age norm, or who in other words find it appropriate that older workers retire later, are more positive about the employment of older workers, and hiring them after (early) retirement. In addition, they are more likely to support prolonged employment after state pension age, which is a common institutionalised anchor of managers' retirement age norms (Oude Mulders et al., 2017).

A higher retirement age norm represents a more positive view about older workers, since finding later retirement of older workers in general appropriate implies their fitness for work until higher ages. Conversely, a lower retirement age norm indicates a more negative view of older workers, as a preference for earlier retirement of older workers implies that they are unfit for work until higher ages and should "make way" for younger workers (Radl, 2012). As such, it is expected here that managers holding a higher retirement age norm are more in favour of older workers in different types of employment decisions:

H1. Employers that hold a higher retirement age norm are less likely to prefer younger workers, and more likely to prefer older workers for employment decisions, than employers that hold a lower retirement age norm.

\section{Stereotypes about younger and older workers}

Stereotypical perceptions of workers of different ages are common and have been shown in many instances to affect labour market behaviour of both employers and employees themselves

Employers' age-related norms 
IJM

41,5

526

(Gordon and Arvey, 2004). Research on age discrimination has predominantly focused on negative perceptions of older workers, such as their (perceived) lower ability and motivation, and overall lower productivity than younger workers, although there are also studies refuting such stereotypes and implying that job performance may improve with age (Posthuma and Campion, 2009; Ng and Feldman, 2012). Some studies also pay explicit attention to positive characteristics that are predominantly perceived to be attributable to older workers, such as reliability, organisational commitment and social skills towards colleagues and customers (Kite et al., 2005; Van Dalen et al., 2010; Bal et al., 2011). Stereotypes about younger workers are commonly the opposite of those about older workers.

Van Dalen et al. (2010) argue that there are two main dimensions underlying evaluations of older workers: "hard qualities" and "soft qualities". Hard qualities are qualities such as mental and physical capacity, willingness to learn new skills and the ability to adapt to new technologies, whereas soft qualities are qualities that could be classified as organisational citizenship behaviour, such as social skills, commitment and reliability. Hard qualities are, in the perception of employers and employees, more directly tied to productivity, whereas soft qualities are more tied to pro-social behaviour that benefits the organisation as a whole. This distinction between hard and soft qualities may also be useful to evaluate the effect of stereotypical views on ageist employment practices. A difference in the relevance of these stereotypes for different employment decisions is not a priori clear, but in general, it is expected that more positive evaluations of older workers lead to employment decisions that are more favourable to older workers, or at least less explicitly favourable to younger workers:

$H 2 a$. Employers that find soft qualities relatively more attributable to older than to younger workers are less likely to prefer younger workers, and more likely to prefer older workers for employment decisions, than employers that find soft qualities less attributable to older workers.

$H 2 b$. Employers that find hard qualities relatively more attributable to older than to younger workers are less likely to prefer younger workers, and more likely to prefer older workers for employment decisions, than employers that find hard qualities less attributable to older workers.

\section{Methods}

Data

Survey data were collected from Dutch employers between December of 2016 and March of 2017. First, a stratified sample of 6,000 organisations with at least ten employees was drawn, covering all sectors of industry (except the agricultural sector). The sample was stratified according to size and sector, so that small organisations (between 10 and 50 employees) and organisations in the services sector were undersampled, whereas large organisations (with more than 250 employees) and organisations in the public sector were oversampled. This was done to ensure sufficient responses from different types of relevant organisations. However, this means data are not fully representative of the population of employers in the Netherlands.

A hard copy survey was sent to the organisations, along with an enclosed letter introducing the research and inviting them to participate. The letter also contained a unique code with which respondents could access an online version of the questionnaire. Two reminders were sent over the course of four months, the first containing only a reminder letter, and the second also containing a new hard copy of the survey. The survey was addressed to the director or CEO of the organisation, although the letter stated also other employees knowledgeable about the organisation's background and practices could participate on the organisation's behalf. In total, 1,358 completed questionnaires were returned, implying a response rate of 23 per cent. This rate is lower than usually found in 
surveys targeting individual respondents, but comparable to other large organisational surveys (Baruch and Holtom, 2008). Half of the responses were sent in hard copy, the other half were completed through the online version of the survey.

This study is interested in the relation between, on the one hand, individual conceptions of the retirement age norm and stereotypes, and on the other hand, preferences for older or younger workers in several employment decisions. It is therefore relevant to only study respondents that have authority to make such decisions, since respondents without such authority may obscure relevant effects (Landy, 2008). Therefore, surveys filled in by HR employees or other types of non-authoritative employees $(n=372)$ were removed before analysis, and only surveys filled in by owners, CEOs, directors, top managers and HR managers were retained. Furthermore, 26 responses were removed before analysis because of missing data on the dependent variables, leaving 960 employer responses for analysis.

Item non-response on the independent variables was very low, ranging between 0.4 and 1.8 per cent for the structural organisational and manager characteristics, 2.9 per cent for the retirement age norm, and 4.5 and 5.1 per cent for the hard qualities and soft qualities stereotype variables. Missing values were imputed using single stochastic imputation (Stata command "mi impute chained"), which has been found acceptable with such a low prevalence of missing values (Enders, 2010).

\section{Measures}

Dependent variables. Respondents were asked to rate whether they favoured younger or older workers for a number of employment decisions. The question was "Do you generally prefer younger or older workers when it comes to [...]", hiring a new employee; offering training; offering a permanent contract. Answers were given on a five-point scale, with anchors "Prefer younger workers" (1), "Neutral" (3) and "Prefer older workers" (5).

Independent variables. Several structural characteristics of the organisations were collected through the questionnaire and included in the analysis. Sector was assessed by asking in which sector of industry the organisation operated (reduced to represent three main sectors: Public sector; Industry; Services and trade). Organisational size was assessed by asking for the number of employees (reduced to three main categories, based on Eurostat's Structural Business Statistics classification: small (10 to 49 employees); medium (50 to 249 employees); large (250 employees or more). Employers were also asked to indicate the percentage of their workforce that were older workers (i.e. older than 50 years of age); working on a flexible contract (such as a temporary contract); and working part-time. For the analysis, percentages were divided by 100 , so they can be read as proportions (i.e. ranging between 0 and 1) to ease interpretation.

Respondents were asked for their sex and age, which are controlled for in the analysis as manager's characteristics. Further, they provided their retirement age norm by answering the question "After what age do you find someone generally too old to work at least 20 hours a week?" This is the common way to assess the upper limit of the retirement age norm (Radl, 2012). Answers were truncated between 50 and 90 due to a small number of unrealistic answers (i.e. respondents mentioning a retirement age norm of 15 or 99). This did not, however, affect substantive results.

Stereotypes of employers were assessed with the following two questions: "To what extent do you find the following characteristics applicable to employees of 50 years and older?" and "To what extent do you find the following characteristics applicable to employees of 35 years and younger?" For both questions, six items were presented: physical capacity; social skills; willingness to learn; reliability; loyalty; and skilful with new technology. Answers ranged on a four-point scale (Not/To a small extent; Somewhat; To a strong extent; To a very strong extent). Based on the study by Van Dalen et al. (2010), this analysis distinguishes between hard qualities
Employers' age-related norms 
IJM

528

(physical capacity; willingness to learn; skilful with new technology) and soft qualities (social skills; reliability; loyalty). Then, relative scores were computed, indicating the level to which those characteristics apply to older workers compared to younger workers (Karpinska et al., 2013b). Scores above 1 thus indicate that respondents find those qualities more attributable to older workers, whereas scores below 1 indicate that respondents find the characteristics more attributable to younger workers. Descriptive statistics for the independent variables are presented in Table I.

\section{Results}

Table II presents the answer distributions for the three dependent variables. Although distributions vary, a common finding for all three dependent variables is that very few employers prefer older workers. Preferences for younger workers are much more common, especially when it comes to hiring. More than half of the employers (58 per cent) have a strong or slight preference for younger workers when it comes to hiring a new employee. Preferences for younger workers are less pronounced when it comes to training and offering a permanent contract, but still 21 and 19 per cent of employers, respectively, have either a strong or a slight preference for younger workers for those decisions.

Next, for the multivariate analyses, categorical variables were created that indicated "Preference for younger workers" (Answers 1 and 2), "Neutral" (Answer 3) and "Preference for older workers" (Answers 4 and 5), and multinomial logistic regression was applied to study

\begin{tabular}{lcc}
\hline & \% or mean & SD \\
\hline Organisational characteristics & & \\
Sector & & \\
$\quad$ Industry & $36 \%$ & \\
Services and trade & $31 \%$ & 760.42 \\
Public sector & $34 \%$ & \\
Size & 312.98 & \\
Small (10-49 employees) & $35 \%$ & 0.18 \\
Medium (50-249 employees) & $39 \%$ & 0.16 \\
Large (250 or more employees) & $26 \%$ & 0.32 \\
Proportion of older employees & 0.32 & \\
Proportion of employees on a flexible contract & 0.14 & \\
Proportion of part-time employees & 0.39 & \\
Manager characteristics & & \\
Sex & & 3.71 \\
$\quad$ Male & $68 \%$ & 0.37 \\
Female & $32 \%$ & 0.33 \\
Age & 51.80 & \\
Retirement age norm & 67.17 & \\
Hard qualities stereotypes & 0.84 & \\
Soft qualities stereotypes & 1.15 &
\end{tabular}

Table II. Distribution of answers on the dependent variables

\begin{tabular}{lccccc}
\hline & Prefer younger workers & & Neutral & Prefer older workers \\
& 1 & 2 & 3 & 4 & 5 \\
\hline Hiring $(\%)$ & 32 & 26 & 40 & 2 & 1 \\
Training (\%) & 6 & 15 & 76 & 2 & 0 \\
Permanent contract (\%) & 7 & 12 & 79 & 1 & 0 \\
\hline
\end{tabular}


the relation between organisational and managerial structural characteristics, managers' retirement age norms and stereotypes, and their ageist preferences in the three employment decisions. For all analyses, average marginal effects are presented, indicating how the probability of an answer changes relative to the probabilities presented in Table II, with a one unit change in the independent variable, averaged over all organisations (i.e. without independent variables fixed on some value). The marginal effects of each independent variable sum to zero by definition.

First, the results for hiring a new employee are presented in Table III. Results show that managers with a higher retirement age norm, in other words who find older workers suitable to continue working up to a higher age, are more likely to be neutral in their hiring preferences. In addition, managers who rate older workers higher on their soft qualities, but not on their hard qualities, are less likely to favour younger workers, and more likely to be neutral. The reverse of this effect implies that managers that find no difference on soft qualities or believe soft qualities are more attributable to younger workers have a stronger preference for younger workers. Further, larger organisations tend to be more neutral in their preferences for hiring a new employee. Organisations with many employees on a flexible contract are more likely to favour older workers. Female managers are more likely than male managers to be neutral in their hiring preferences, whereas males are more likely to favour younger workers.

Results for offering training to an employee are presented in Table IV. Results show that managers with a higher retirement age norm are less likely to favour younger workers and more likely to be neutral. In addition, when older workers are rated strongly on their soft qualities, relative to younger workers, employers are more likely to offer training to older workers. Further, organisations in the industry sector are less likely to be neutral, while larger organisations are less likely to prefer younger workers and more likely to be neutral. Here, organisations with many employees on a flexible contract are more likely to prefer younger workers to offer training to, while organisations with many part-time employees

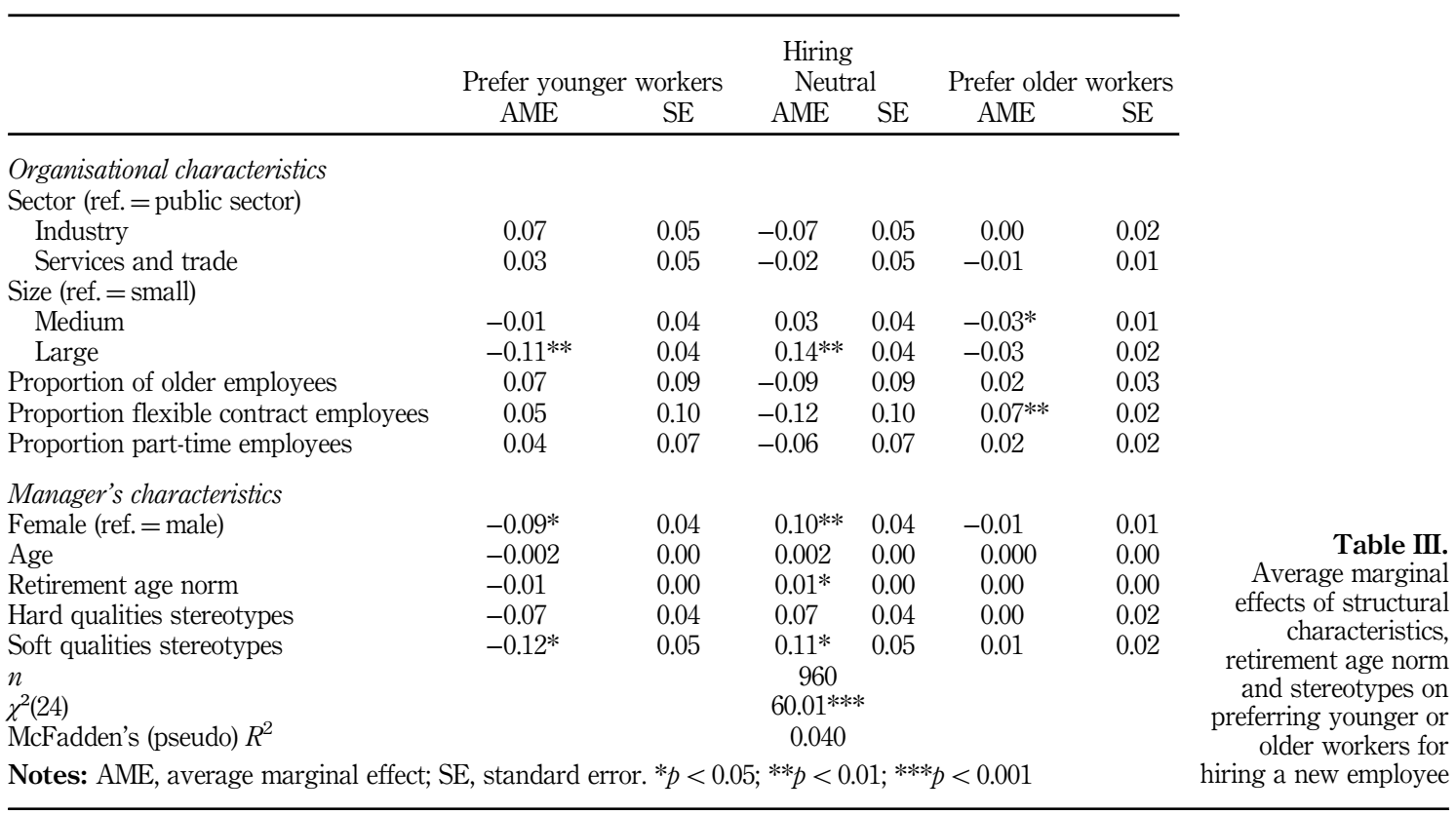

Employers' age-related norms 


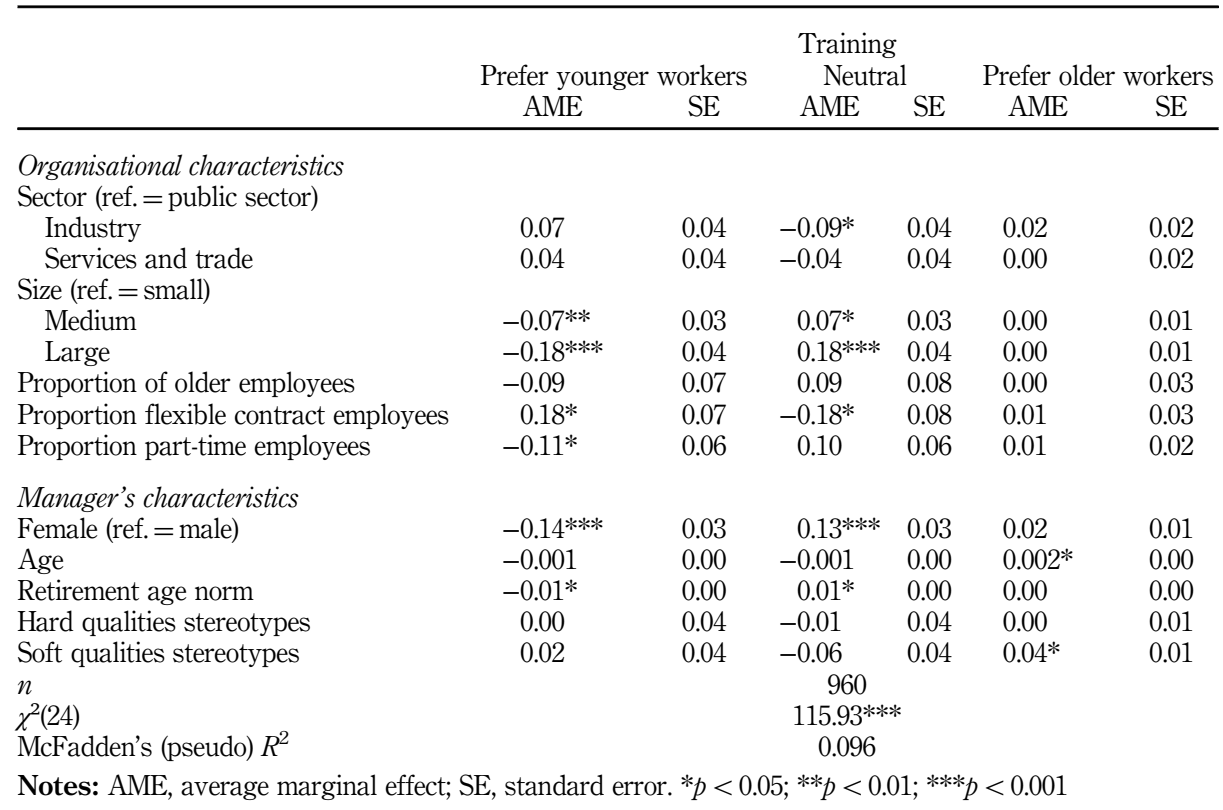

are less likely to prefer younger workers. Female managers are more likely than male managers to be neutral, and less likely to prefer younger workers. Older managers are more likely to prefer older workers for training, although the effect size is very small.

Results for offering a permanent contract are presented in Table V. Here, as with the other two outcome variables, a higher retirement age norm has a positive effect on having a neutral stance or no preference, rather than a preference for younger workers. Stereotypes about relative applicability of hard or soft qualities to younger or older workers are not related to ageist preferences for offering a permanent contract. Further, organisations in the industry sector are more likely to favour younger workers, and large organisations are more likely to be neutral. When it comes to offering a permanent contract, organisations with many flexible contract employees are much more likely to favour younger workers. Again, female managers are more likely than male managers to be neutral, as opposed to favouring younger workers. Older managers are slightly more likely to be neutral.

\section{Discussion}

This paper has studied the roles that employers' social norms about the appropriate timing of retirement and their age-related stereotypical views of younger and older workers play for their ageist preferences in three different types of employment decisions. The results show, first, that many employers have a strong preference for younger workers, especially when it comes to hiring a new employee (58 per cent). While more employers are neutral in their preferences for providing training to an employee (76 per cent) or offering a permanent contract (79 per cent), still respectively 21 and 19 per cent outright admit their preference for younger workers for offering training or offering a permanent contract, whereas preferences for older workers are almost non-existent.

Second, employers that hold a higher retirement age norm, or in other words find older workers employable until higher ages (Radl, 2012) are less likely to favour younger workers, and more likely to be age neutral in providing training and offering a permanent contract. 


\begin{tabular}{|c|c|c|c|c|c|c|c|}
\hline & \multicolumn{6}{|c|}{ Permanent contract } & \multirow{3}{*}{$\begin{array}{r}\text { Employers' } \\
\text { age-related } \\
\text { norms }\end{array}$} \\
\hline & \multicolumn{2}{|c|}{ Prefer younger workers } & \multicolumn{2}{|c|}{ Neutral } & \multicolumn{2}{|c|}{ Prefer older workers } & \\
\hline & AME & $\mathrm{SE}$ & AME & $\mathrm{SE}$ & AME & $\mathrm{SE}$ & \\
\hline \multicolumn{8}{|l|}{ Organisational characteristics } \\
\hline \multicolumn{8}{|l|}{ Sector (ref. = public sector) } \\
\hline Industry & $0.10 *$ & 0.04 & $-0.10^{*}$ & 0.04 & -0.01 & 0.01 & \\
\hline Services and trade & 0.05 & 0.04 & -0.03 & 0.04 & -0.01 & 0.01 & 53 \\
\hline \multicolumn{8}{|l|}{ Size $($ ref. $=$ small $)$} \\
\hline Medium & -0.03 & 0.03 & 0.02 & 0.03 & 0.00 & 0.01 & \\
\hline Large & $-0.10 * *$ & 0.03 & $0.11 * *$ & 0.04 & -0.01 & 0.02 & \\
\hline Proportion of older employees & 0.11 & 0.07 & -0.08 & 0.07 & -0.03 & 0.03 & \\
\hline Proportion flexible contract employees & $0.34^{* * * *}$ & 0.07 & $-0.35^{* * * *}$ & 0.07 & 0.02 & 0.02 & \\
\hline Proportion part-time employees & -0.01 & 0.05 & 0.04 & 0.06 & -0.03 & 0.02 & \\
\hline \multicolumn{8}{|l|}{ Manager's characteristics } \\
\hline Female (ref. = male) & $-0.15^{* * *}$ & 0.03 & $0.16^{* * * *}$ & 0.03 & -0.01 & 0.01 & Table \\
\hline Age & $-0.004^{*}$ & 0.00 & $0.003^{*}$ & 0.00 & 0.000 & 0.00 & Average marginal \\
\hline Retirement age norm & $-0.01 * *$ & 0.00 & $0.01 * *$ & 0.00 & 0.00 & 0.00 & effects of structural \\
\hline Hard qualities stereotypes & -0.05 & 0.04 & 0.07 & 0.04 & -0.01 & 0.01 & characteristics, \\
\hline Soft qualities stereotypes & -0.07 & 0.04 & 0.06 & 0.04 & 0.01 & 0.01 & retirement age norm \\
\hline \multicolumn{7}{|l|}{$\begin{array}{l}n \\
\gamma^{2}(24)\end{array}$} & $\begin{array}{l}\text { and stereotypes on } \\
\text { preferring vounger or }\end{array}$ \\
\hline$\chi^{2}(24)$ & & & 110.19 ** & & & & older workers for \\
\hline \multicolumn{7}{|l|}{ McFadden's (pseudo) $R^{2}$} & offering a permanent \\
\hline \multicolumn{8}{|c|}{ Notes: AME, average marginal effect; SE, standard error. $* p<0.05 ; * * p<0.01 ; * * * p<0.001$} \\
\hline
\end{tabular}

However, a higher retirement age norm does not translate into a preference for older workers over younger workers for any of the employment decisions studied here. $H 1$ is thus partly supported: employers that hold a higher retirement age norm are less likely to prefer younger workers, but not more likely to prefer older workers, than employers that hold a lower retirement age norm. As such, the effect of retirement age norms are not as strong as in earlier experimental work studying decisions by individual managers (Karpinska et al., 2013a, b; Oude Mulders et al., 2014).

Third, employers' stereotypes about the extent to which "hard" and "soft" qualities (Van Dalen et al., 2010) are attributable to younger and older workers have a less profound effect on ageist preferences in employment. Only when employers perceive soft qualities (social skills, reliability and loyalty) to be more attributable to older workers than to younger workers, they are a little less likely to prefer younger workers for hiring, slightly more likely to prefer older workers for training, while there are no significant effects for offering a permanent contract. This may be because the decision to offer a permanent contract is more based on an appraisal of actual job performance, whereas hiring a new employee and offering training are more susceptible to ageist preferences. $H 2 a$ is thus partly supported. A better perception of older workers' hard qualities (physical capacity, willingness to learn and being skilful with new technologies) relative to hard qualities of younger workers does not lead to less ageist preferences. $H 2 b$ is thus rejected. This implies that employers rate the productivity and utility of older and younger workers for their organisation on somewhat different dimensions (Kite et al., 2005; Bal et al., 2011), and older workers may be better off emphasising their strong soft qualities than trying to improve their declining hard qualities (Van Dalen et al., 2010). It also implies stereotypes are pervasive and their effects on employment decisions may be to some degree inevitable (Gordon and Arvey, 2004; Roscigno et al., 2007; Neumark and Button, 2014).

Other interesting findings include employers from larger organisations being much more neutral in their preferences than employers from smaller organisations. This effect may be 
IJM

41,5

532

attributable to larger organisations being more compliant with explicit regulations that try to prevent ageism, but also to their more active benchmarking against competitors (Ollier-Malaterre et al., 2013). In addition, their larger size may make it easier to employ a mix of younger and older workers, whereas smaller organisations that focus on a few core tasks may have more explicit preferences for younger workers with their perceived higher overall productivity. Further, it was found that female employers were less ageist in their preferences for all types of employment decisions than male employers were. This may be because female managers are more likely to experience ageism themselves which may make them more sensitive to the negative effects that explicit preferences for younger workers may have on older workers (Duncan and Loretto, 2004; Radl, 2012; Jyrkinen, 2014).

Some limitations of this study should be acknowledged. First, the dependent measures in this study measure stated preferences of employers for younger and older workers in certain employment contexts, rather than actual behaviour. It is not clear that these stated preferences translate directly into behaviour, especially the measures for providing training and offering a permanent contract, since these decisions are made regarding employees that are already known to the employer, and personal information may weaken ageist bias (Landy, 2008). On the other hand, there may be a degree of social desirability in the answers provided to this question, which would mean the degree of employers' ageist preferences would be underestimated (Lindner et al., 2014). Future studies may therefore add to these findings by relating employers' age-related social norms and stereotypes to actual behaviour in employment decisions. Second, this study only analyses data from a single country, the Netherlands, meaning its particular institutional context may influence the results and limit generalisability to other contexts. Since age-related social norms and stereotypes can be culturally influenced (North and Fiske, 2015; Marcus and Fritzsche, 2016), it would be valuable for future studies to study these relationships in different cultural and institutional contexts.

In conclusion, this study has demonstrated that employers' retirement age norms and age-related stereotypes about younger and older workers are related to their ageist preferences in different types of employment decisions. Especially higher retirement age norms lead to weaker preferences for younger workers, implying it is necessary to continue trying to normalise the employment of older workers at higher ages, as this is what appears to slowly lead to higher societal retirement age norms (Radl, 2012; Oude Mulders et al., 2017). In addition, older workers may be better off emphasising their strong soft skills, such as their organisational citizenship behaviour, rather than trying to improve their declining hard skills, because employers appear to especially value older workers based on their soft skills.

\section{References}

Ageism (n.d.), Oxford English Dictionary, 3rd ed., Oxford University Press, available at: www.oed.com/ view/Entry/3840 (accessed 2 July 2019).

Bal, A.C., Reiss, A.E.B., Rudolph, C.W. and Baltes, B.B. (2011), "Examining positive and negative perceptions of older workers: a meta-analysis", The Journals of Gerontology, Series B: Psychological Sciences and Social Sciences, Vol. 66 No. 6, pp. 687-698.

Baruch, Y. and Holtom, B.C. (2008), "Survey response rate levels and trends in organizational research", Human Relations, Vol. 61 No. 8, pp. 1139-1160.

Conen, W.S., Van Dalen, H.P. and Henkens, K. (2012), "Ageing and employers' perceptions of labour costs and productivity: a survey among European employers", International Journal of Manpower, Vol. 31 No. 6, pp. 629-647.

Duncan, C. and Loretto, W. (2004), "Never the right age? Gender and age-based discrimination in employment", Gender, Work and Organization, Vol. 11 No. 1, pp. 95-115. 
Enders, C.K. (2010), Applied Missing Data Analysis, The Guilford Press, New York, NY.

Gordon, R.A. and Arvey, R.D. (2004), "Age bias in laboratory and field settings: a meta-analytic investigation", Journal of Applied Social Psychology, Vol. 34 No. 3, pp. 468-492.

Griffin, B., Bayl-Smith, P. and Hesketh, B. (2016), "The longitudinal effects of perceived age discrimination on the job satisfaction and work withdrawal of older employees", Work, Aging and Retirement, Vol. 2 No. 4, pp. 415-427.

Harris, K., Krygsman, S., Waschenko, J. and Rudman, D.L. (2018), "Ageism and the older worker: a scoping review", The Gerontologist, Vol. 58 No. 2, pp. e1-e14.

Heisig, J.P. and Radl, J. (2017), “Adding scars to wrinkles? Long-run effects of late-career job loss on retirement behavior and personal income", Work, Aging and Retirement, Vol. 3 No. 3, pp. 257-272.

Henkens, K. (2005), "Stereotyping older workers and retirement: the managers' point of view", Canadian Journal on Aging, Vol. 24 No. 4, pp. 353-366.

Jyrkinen, M. (2014), "Women managers, careers and gendered ageism”, Scandinavian Journal of Management, Vol. 30 No. 2, pp. 175-185.

Karpinska, K., Henkens, K. and Schippers, J. (2013a), "Hiring retirees: impact of age norms and stereotypes”, Journal of Managerial Psychology, Vol. 28 Nos 7/8, pp. 886-906.

Karpinska, K., Henkens, K. and Schippers, J. (2013b), "Retention of older workers: impact of managers' age norms and stereotypes”, European Sociological Review, Vol. 29 No. 6, pp. 1323-1335.

Kite, M.E., Stockdale, G.D., Whitley, B.E. and Johnson, B.T. (2005), "Attitudes toward younger and older adults: an updated meta-analytic review”, Journal of Social Issues, Vol. 61 No. 2, pp. 241-266.

Landy, F.J. (2008), "Stereotypes, bias, and personnel decisions: strange and stranger", Industrial and Organizational Psychology, Vol. 1 No. 4, pp. 379-392.

Liefbroer, A.C. and Billari, F.C. (2010), "Bringing norms back in: a theoretical and empirical discussion of their importance for understanding demographic behaviour", Population, Space and Place, Vol. 16 No. 4, pp. 287-305.

Lindner, N.M., Graser, A. and Nosek, B.A. (2014), "Age-based hiring discrimination as a function of equity norms and self-perceived objectivity”, PLOS One, Vol. 9 No. 1, pp. 1-6.

Marchiondo, L.A., Gonzales, E. and Williams, L.J. (2019), "Trajectories of perceived workplace age discrimination and long-term associations with mental, self-rated, and occupational health", The Journals of Gerontology, Series B: Psychological Sciences and Social Sciences, Vol. 74 No. 4, pp. 655-663.

Marcus, J. and Fritzsche, B.A. (2016), "The cultural anchors of age discrimination in the workplace: a multilevel framework", Work, Aging and Retirement, Vol. 2 No. 2, pp. 217-229.

Neumark, D. and Button, P. (2014), "Did age discrimination protections help older workers weather the Great Recession?”, Journal of Policy Analysis and Management, Vol. 33 No. 4, pp. 566-601.

Ng, T.W.H. and Feldman, D.C. (2012), "Evaluating six common stereotypes about older workers with meta-analytical data", Personnel Psychology, Vol. 65 No. 4, pp. 821-858.

North, M.S. and Fiske, S.T. (2015), "Modern attitudes toward older adults in the aging world: a cross-cultural meta-analysis", Psychological Bulletin, Vol. 141 No. 5, pp. 993-1021.

OECD (2014), Ageing and Employment Policies: Netherlands 2014: Working Better with Age, OECD Publishing, Paris, available at: http://dx.doi.org/10.1787/9789264208155-en

OECD (2017), Pensions at a Glance 2017: OECD and G20 Indicators, OECD Publishing, Paris, available at: http://dx.doi.org/10.1787/pension_glance-2017-en

Ollier-Malaterre, A., McNamara, T., Matz-Costa, C. and Pitt-Catsouphes, M. (2013), "Looking up to regulations or down at the bottom line: how institutional logics affect the prevalence of age-related HR practices”, Human Relations, Vol. 66 No. 10, pp. 1373-1395.

Oude Mulders, J., Henkens, K. and Schippers, J. (2017), “European top managers' age-related workplace norms and their organizations' recruitment and retention practices regarding older workers", The Gerontologist, Vol. 57 No. 5, pp. 857-866. 
IJM

41,5
Oude Mulders, J., Van Dalen, H.P., Henkens, K. and Schippers, J. (2014), "How likely are employers to rehire older workers after mandatory retirement? A vignette study among managers", De Economist, Vol. 162 No. 4, pp. 415-431.

Oude Mulders, J., Henkens, K., Liu, Y., Schippers, J. and Wang, M. (2018), "Managers' interview invitation decisions about older job applicants: human capital, economic conditions and job demands", Ageing \& Society, Vol. 38 No. 4, pp. 839-864.

Posthuma, R.A. and Campion, M.A. (2009), "Age stereotypes in the workplace: common stereotypes, moderators, and future research directions", Journal of Management, Vol. 35 No. 1, pp. 158-188.

Radl, J. (2012), "Too old to work, or too young to retire? The pervasiveness of age norms in Western Europe", Work, Employment and Society, Vol. 26 No. 5, pp. 755-771.

Roscigno, V.J., Mong, S., Byron, R. and Tester, G. (2007), "Age discrimination, social closure and employment”, Social Forces, Vol. 86 No. 1, pp. 313-334.

Settersten, R.A. and Hagestad, G.O. (1996), "What's the latest? II. Cultural age deadlines for educational and work transitions", The Gerontologist, Vol. 36 No. 5, pp. 602-613.

Stypinska, J. and Turek, K. (2017), "Hard and soft age discrimination: the dual nature of workplace discrimination", European Journal of Ageing, Vol. 14 No. 1, pp. 49-61.

Van Dalen, H.P., Henkens, K. and Schippers, J. (2010), "Productivity of older workers: perception of employers and employees", Population and Development Review, Vol. 36 No. 2, pp. 309-330.

Visser, M., Gesthuizen, M., Kraaykamp, G. and Wolbers, M.H.J. (2016), "Trends in labour force participation of older men: examining the influence of policy reforms, normative change and deindustralization in the Netherlands, 1992-2009", Economic and Industrial Democracy, Vol. 37 No. 3, pp. 425-447.

Wanberg, C.R., Kanfer, R., Hamann, D.J. and Zhang, Z. (2016), “Age and reemployment success after job loss: an integrative model and meta-analysis", Psychological Bulletin, Vol. 142 No. 4, pp. 400-426.

Weiss, E.M. and Maurer, T.J. (2004), "Age discrimination in personnel decisions: a reexamination”, Journal of Applied Social Psychology, Vol. 34 No. 8, pp. 1551-1562.

Zaniboni, S. (2015), "The interaction between older workers' personal resources and perceived age discrimination affects the desired retirement age and the expected adjustment", Work, Aging and Retirement, Vol. 1 No. 3, pp. 266-273.

\section{Corresponding author}

Jaap Oude Mulders can be contacted at: j.oude.mulders@rug.nl

For instructions on how to order reprints of this article, please visit our website: 